\title{
Heavy Oil Dilution
}

\author{
P. Gateau ' , I. Hénaut ' ${ }^{1}$ L. Barré ${ }^{1}$ and J.F. Argillier ${ }^{1}$ \\ 1 Institut français du pétrole, 1 et 4, avenue de Bois-Préau, 92852 Rueil-Malmaison Cedex - France \\ e-mail: patrick.gateau@ifp.fr - isabelle.henaut@ifp.fr - loic.barre@ifp.fr - j-francois.argillier@ifp.fr
}

Résumé - Dilution des bruts lourds - Les pétroles bruts lourds ne peuvent être transportés par pipeline sans réduction préalable de leur viscosité. Pour ce faire, la méthode la plus couramment employée est la dilution par des hydrocarbures légers. Dans ce cas, la viscosité du mélange dépend uniquement du taux de dilution et des viscosités et densités respectives de l'huile lourde et du diluant. L'ajout d'un solvant polaire à une solution d'asphaltènes dans du toluène permet d'agir sur la structure colloïdale des asphaltènes. Ceci conduit à une diminution de la viscosité relative de la solution. Des mesures effectuées par diffusion des rayons $\mathrm{X}$ aux petits angles indiquent que le rayon de giration des agrégats d'asphaltènes diminue conjointement. De même, en mélangeant des hydrocarbures avec des solvants comportant des groupements polaires, il est montré que l'efficacité de la dilution des bruts lourds est améliorée. La théorie de Hansen peut être utilisée pour sélectionner les solvants les plus efficaces. À taux de dilution constant, une augmentation du paramètre de polarité ou du paramètre représentatif des liaisons hydrogène se traduit par une diminution de la viscosité relative du brut dilué. Néanmoins, les produits comportant de fortes liaisons hydrogène sont généralement plus visqueux que les hydrocarbures. L'effet de leur interaction avec les asphaltènes s'en trouve masqué lorsque les résultats sont exprimés en termes de viscosité absolue. Seuls les solvants polaires donnant peu de liaisons hydrogène permettent d'obtenir une réduction significative de la viscosité du brut dilué.

\begin{abstract}
Heavy Oil Dilution - Heavy crude oils cannot be transported by pipeline without a prior reduction of their viscosity. This is commonly obtained by blending the oil with light hydrocarbons. In that case, the resulting viscosity of the mixture depends only on the dilution rate, on the respective viscosities and densities of the oil, and of the diluent. The addition of a polar solvent to a solution of asphaltenes in toluene acts on the colloidal structure of the asphaltenes. The relative viscosity of the solution decreases. Small-angle X-ray scattering (SAXS) measurements show that the radius of gyration of the aggregates of asphaltenes decreases too. In the same way, by mixing hydrocarbons and solvents owning polar functional groups in their molecule, it is shown that the efficiency of the dilution of heavy crude oils is enhanced. Hansen's theory can be used to screen the solvent efficiency. At constant dilution rate, the higher the polarity parameter or the hydrogen bonding parameter of the solvent, the greater the relative viscosity reduction of the diluted crude oil. Nevertheless, solvent owning high hydrogen bonding are generally more viscous than hydrocarbons. The influence of their interactions with the asphaltenes is hidden when the results are expressed in absolute viscosity. Only polar solvents giving few hydrogen bonding give a significant reduction of the viscosity of the diluted crude oil.
\end{abstract}




\section{INTRODUCTION}

Crude oils are usually transported from the producing field to the refinery by pipeline. Concerning heavy crude oils with API gravity less than $15^{\circ}$, this method requires special facilities. The major problem with this type of crudes that come along with high densities is their high viscosities, ranging from a few thousand to million of centipoises at reservoir temperature while $400 \mathrm{cP}$ is a classical maximum desired pipeline viscosity. The only real solution currently available is to add a diluent to reduce viscosity even if oil in water emulsions and core annular flow seem to be promising solutions for the future.

Condensates have been used until the end of the 80 's to transport almost the whole production of the Canadian crude [1-3]. There are some disadvantages to use condensates for heavy oil dilution. The availability of these components is related to the natural gas demand [1, 4]. In some likelihood established at the end of the 1980th [3], which have been confirmed later [5], the production of condensate during the 2000th could not be sufficient to cover the whole demand of thinner, related to the increase of the heavy oil production. Moreover, these products are not good solvents for asphaltenes and flocculation may occur. This can lead to a partial plugging of the lines $[3,6]$. Another choice to dilute heavy oils is to use a light crude, with an API gravity range from 35 to 42 [3, 4]. Light oils are less efficient in reducing the viscosity of heavy oils than condensates [2] and they are subjected to the same limitations of availability and of compatibility with the asphaltenes. Naphtha seems to be an interesting alternative to the use of condensates $[3,7]$. Because of its high API density, it is very efficient in diluting heavy oils. Naphtha shows a good compatibility with asphaltenes and is easily reusable. Dilution with naphtha associated with solvent recycling has been used for Canadian crude from Cold Lake and from Lloydminster during the 1990th and is at present the selected process for the Sincor project (Venezuela).

For mixtures of liquid hydrocarbons, including crude oils and fractions, the viscosity-composition curve is generally a monotonic, concave-upward function, and rarely goes through a minimum [8]. In a general way, the lower the viscosity of the diluent the lower the viscosity of the diluted crude. However, as the viscosity ratio between the heavy oil and the solvent is very important, simple mixing rules do not apply. Empirical models based on multiple regression analysis have been developed to predict the viscosity of diluted heavy oils or bitumen [9].

Use of organic solvents other than hydrocarbons has been considered by some authors. Methyl tert-butyl ether (MTBE) and tert-amyl methyl ether (TAME) have been studied in laboratory experiments as alternative thinners for heavy oils $[10,11]$. These solvents are generally used in gasoline to improve octane number. No comparison was made between hydrocarbons and these compounds. Alcohols, especially pentanol is at least twice as effective as kerosene in reducing the viscosity of heavy oil [12]. This suggests the supplementary reduction of the viscosity to be due to interactions between the hydroxyl functions and some functionalities of the asphaltenes [13].

From an economical point of view, any improvement of the efficiency of the thinner will be a benefit for the process, by reducing the amount of solvent needed to get an acceptable viscosity, and therefore allowing a greater quantity of crude to be transported. The study presented here is aimed at showing that the polarity of the thinner may have some influence on the viscosity reduction of the solution.

\section{SAMPLES AND METHODS}

\subsection{Heavy Oil Samples}

The heavy oil (Oil A) used in this work is a Venezuelan heavy crude oil. The API density of this oil is 8.5. SARA analysis (quantification of saturates, aromatics, resins and asphaltenes) have been performed on $\mathrm{C}_{20}{ }^{+}$fraction (boiling point $>344^{\circ} \mathrm{C}$ ) of the dead oil using heptane as precipitating solvent of asphaltenes. Results of ultimate analysis of each fraction are given in Table 1.

TABLE 1

Properties of the Venezuelan heavy oil sample Oil A

\begin{tabular}{l|c|c|c|c|c|c}
\cline { 2 - 7 } & \multirow{2}{*}{ Weight \% } & \multicolumn{5}{|c}{$\begin{array}{c}\text { \% weight on } \mathrm{C}_{20}{ }^{+} \\
\text {SARA fractions }\end{array}$} \\
\cline { 3 - 7 } & & $\mathrm{C}$ & $\mathrm{H}$ & $\mathrm{N}$ & $\mathrm{O}$ & $\mathrm{S}$ \\
\hline Asphaltenes & 14.1 & 83.8 & 7.5 & 1.3 & 1.7 & 4.8 \\
Resins & 37.3 & 82.8 & 8.9 & 1.5 & 2.0 & 4.3 \\
Aromatics & 37.2 & 84.3 & 10 & $<0.3$ & 1.1 & 4.0 \\
Saturates & 11.4 & 86.6 & 13 & $<0.3$ & $<0.2$ & $<0.1$ \\
\hline
\end{tabular}

\subsection{Methods}

Viscosity measurements of diluted crude oil were performed using a controlled stress rheometer AR2000 from TA Instruments with a cone-plate geometry $\left(\varnothing 6 \mathrm{~cm}\right.$, angle $\left.2^{\circ}\right)$. A double cylinder Couette geometry was used to measure viscosity of solvent mixtures.

TABLE 2

Chemical composition of naphtha

\begin{tabular}{l|c|c|c}
\hline Chemical family & Weight $\%$ & Molar $\%$ & Volume $\%$ \\
\hline$n$-paraffin & 24.9 & 24.8 & 26.5 \\
Iso-paraffin & 29.4 & 28.1 & 30.9 \\
Cyclic paraffin & 30.9 & 31.3 & 29.9 \\
Aromatic & 14.8 & 15.8 & 12.8 \\
\hline
\end{tabular}


The dilution of the crude oil has been performed using different organic solvents mixed with nonane (Fluka) or naphtha. Naphtha is a petroleum fraction; the composition of the naphtha used in this study determined by gas chromatography is given in Table 2 . The samples have been homogenized by stirring during $24 \mathrm{~h}$.

\section{DILUTION USING A LIGHT HYDROCARBON}

We have reported on Figure 1 the evolution of the viscosity at $20^{\circ} \mathrm{C}$ for different mixtures of Oil A with naphtha. Lederer [14] proposed a modified version of the classic Arrhenius expression to represent the mixture viscosity:

$\log \mu=\left(\frac{\alpha V_{O}}{\alpha V_{O}+V_{S}}\right) \log \mu_{O}+\left(1-\frac{\alpha V_{O}}{\alpha V_{O}+V_{S}}\right) \log \mu_{S}$

where $V_{O}, \mu_{O}, V_{S}, \mu_{S}$ are respectively the volume fraction and the viscosity for the oil $(O)$ and the solvent $(S)$ and where $\alpha$ is an empirical constant varying between 0 and 1 . The fitting of the parameter $\alpha$ to the values presented in Figure 1 using a least-square method leads to the value of 0.4180 for $\alpha$.

Shu [9] defined a generalized expression of $\alpha$ able to represent the viscosity of heavy oils or bitumen diluted with light hydrocarbons. He correlated this parameter with the viscosity ratio and the densities of solvent $\rho_{S}$ and oil $\rho_{O}$ :

$$
\alpha=\frac{17.04\left(\rho_{O}-\rho_{S}\right)^{0.5237} \rho_{O}^{3.2745} \rho_{S}^{1.6316}}{\ln \left(\frac{\mu_{O}}{\mu_{S}}\right)}
$$

The introduction in Equation(2) of the density and viscosity for Oil A and naphtha leads to a $\alpha$ value of 0.4068 .
This value agrees well with $\alpha$ obtained by fitting the experimental values of the viscosity. This is an indication that hydrocarbons reduce the viscosity of heavy oils in the same way. To increase the efficiency of the dilution, other organic products are probably needed.

\section{ACTION OF POLAR SOLVENT ON ASPHALTENES}

Alcohols are known to be more efficient than hydrocarbons to reduce the viscosity of diluted heavy oils $[12,13]$. We can think that it comes from the ability of a polar solvent to act on the structure of the colloidal particles of asphaltenes. To verify this hypothesis, some experiments have been made using the asphaltenes precipitated from the Oil A with pentane (further named I5). We choose to study the system I5/toluene/hexyl alcohol as we know that asphaltenes in toluene are in their colloidal form.

Solutions of $3 \%$ by weight of I5 in hexyl alcohol/toluene mixtures have been prepared. The volume fraction of hexyl alcohol has been varied from 0 to $50 \%$. From optical microscopic observations, it appears that no flocculation occurs even at $50 \%$. Viscosity measurements have been performed at low temperature $\left(3^{\circ} \mathrm{C}\right)$ in order to emphasise the difference of viscosity between the solutions and the solvent. Results are given in terms of relative viscosity defined as $\eta_{\text {rel }}(c, T)=\eta(c, T) / \eta_{\text {diluent }}(T)$. Comparatively, small angle X-ray scattering (SAXS) has been applied. The experiments were made with a scattering wave vector ranging from $10^{-2}$ to $0.2 \AA^{-1}$. The measured intensities were fitted according to the approximation suggested by Zimm [15]. The fits of all solutions were satisfactory and lead to an estimation of the radius of gyration of asphaltenes.

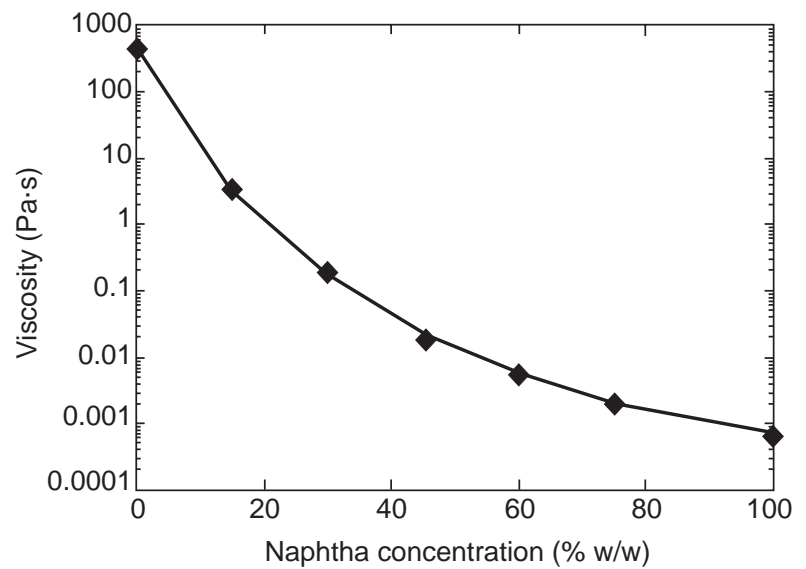

Figure 1

Dilution of Oil A with naphtha. Evolution of the viscosity with the dilution rate.

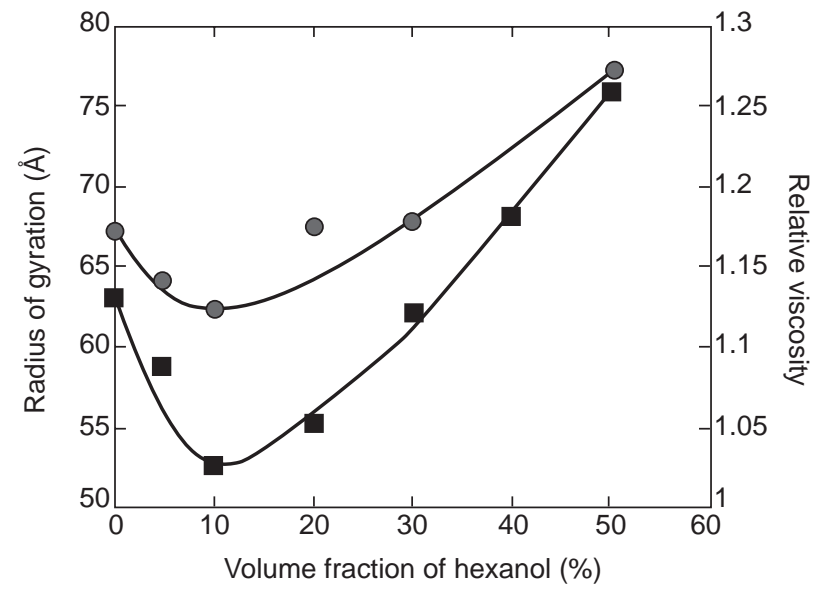

Figure 2

Influence of the volume fraction of hexyl alcohol of 3\% I5 in hexyl alcohol/toluene mixture on the radius of gyration of the asphaltenes at $25^{\circ} \mathrm{C}(\boldsymbol{\square})$, the relative viscosity at $3^{\circ} \mathrm{C}(\bullet)$. 
The obtained values are plotted against the volume fraction of hexyl alcohol (Fig. 2).

The graph shows that there is a minimum for the radius of gyration and for the relative viscosity. This minimum is observed for a hexyl alcohol content of $10 \%$ in toluene. This confirms that hexyl alcohol has an effect on the organization of the asphaltenes in the diluted regime. The decrease of the relative viscosity and of the radius of gyration can be explained by some disruption of the asphaltene particles. One can think that hexyl alcohol is able to establish hydrogen bonds and polar interactions with the asphaltenes and thus replace some of the asphaltenes/asphaltenes interactions. With $10 \%$ of hexyl alcohol, the dissociation phenomenon is at its maximum and all linkages between the elementary particles are broken. An increase of the hexyl alcohol fraction from 10 to $50 \%$ in toluene leads to an increase of both the radius of gyration and the relative viscosity. It is known that the relative viscosity of asphaltenes in a mixed toluene/ heptane tends to increase when the ratio heptane/toluene approachs the flocculation point [16]. Hexyl alcohol, like heptane, is a nonsolvent of the asphaltenes. Then, when all the possible sites able to establish associations between the alcohol functions and the asphaltenes are saturated, hexyl alcohol acts as a flocculant, making the gyration radius and the relative viscosity increase.

\section{INFLUENCE OF THE SOLVENT ON THE VISCOSITY REDUCTION OF THE HEAVY OIL}

By varying the concentration of asphaltenes in maltenes, Hénaut et al. [17] have found the existence of a critical concentration above which the colloidal particles entangle. This structural change dramatically increases the viscosity of the heavy crude oils. Limitation of entanglement will likely reduce the viscosity. This could be enhanced by increasing interactions between the solvent and the polar compounds of the crude oil (mainly the asphaltenes) and breaking the asphaltenes/asphaltenes interactions. From the previous results, polar solvents could assume this function.

According to the theory of Hildebrand and Scott, the parameter $\delta_{t}$ is a measure of molecular interactions. The solubility parameter is defined by:

$$
\delta_{t}=\left(\frac{\Delta E_{L V}}{V_{M}}\right)^{1 / 2}
$$

with $\Delta E_{L V}$ as cohesion energy and $V_{M}$ as molar volume.

In order to be able to distinguish between dispersion forces, polar interactions and hydrogen bonding, Hansen [18] divided this solubility parameter in three parts, i.e. the dispersion part $\delta_{d}$, the polar part $\delta_{p}$ and the hydrogen bonding part $\delta_{h}$, called cohesion energy parameters:

$$
\delta_{t}^{2}=\delta_{d}^{2}+\delta_{p}^{2}+\delta_{h}^{2}
$$

The cohesion energy parameters of solvent mixtures can be calculated from the parameters of each solvent using the following equation:

$$
\delta=\sum_{i=1}^{i=n} \delta_{i} \times V_{i}
$$

where $\delta$ is the Hansen parameter of the mixture (dispersion, polar or hydrogen bonding part), $\delta_{i}$ is the Hansen parameter of the pure solvent $i$ and $V_{i}$ is the volume fraction of the solvent $i$ in the mixture.

The dispersion component of the Hildebrand parameter quantifies the London dispersion forces (or induced dipoleinduced dipole forces). These forces correspond to weak Van der Waals interactions and we can think they will not have any effect on the asphaltene organization. For the two other components, we can expect an influence of their value on the association of the asphaltenes and therefore on the viscosity of the diluted crude. To verify this hypothesis, hydrocarbons have been mixed with organic solvents of different $\delta_{p}$ and $\delta_{h}$ parameters, the resulting parameters of the synthetic mixture being calculated according to Equation (5). The selected hydrocarbons are nonane and naphtha. Nonane is a pure alkane for which polar and hydrogen bonding Hansen parameters are zero. Naphtha is the hydrocarbon mixture commonly used to dilute heavy oils. From its composition (Table 2), one can assume in first approximation that its Hansen parameters are close from those of ASTM Fuel B i.e. $\delta_{d}=15.3, \delta_{p}=0.4, \delta_{h}=0.6$.

To compare dilution efficiency of solvents, results are presented using relative viscosity defined as:

$$
\eta_{\text {rel }}(c, T)=\eta(c, T) / \eta_{\text {diluent }}(T)
$$

with:

$-\eta(c, T)$, the viscosity of the diluted crude at a concentration $c$ and temperature $T(\mathrm{~Pa} \cdot \mathrm{s})$;

$-\eta_{\text {diluent }}(T)$, the viscosity of the thinner at the temperature $T$ (Pa.s).

This representation allows to take no account of the simple dilution effect and on the contrary to emphasis the eventual contribution from organization and structural modifications.

\subsection{Influence of Polarity}

In order to study the influence of the polar component of the Hildebrand parameter, some organic solvents of different $\delta_{p}$ have been selected, keeping as constant as possible the others solubility parameters (Table 3 ).

The solvents have been mixed with nonane and with naphtha at 10 and $50 \% \mathrm{v} / \mathrm{v}$. This allows to get synthetic solvents with polarity parameter varying from 0 to 6.4. Oil A has been diluted with $15 \%$ by weight with the synthetic solvents. Viscosity measurements have been performed at $20^{\circ} \mathrm{C}$. 
TABLE 3

Hansen parameters of nonane and polar cosolvents

\begin{tabular}{l|c|c|c}
\hline Solvent & $\begin{array}{c}\delta_{d} \\
\left(\mathrm{MPa}^{1 / 2}\right)\end{array}$ & $\begin{array}{c}\delta_{p} \\
\left(\mathrm{MPa}^{1 / 2}\right)\end{array}$ & $\begin{array}{c}\delta_{h} \\
\left(\mathrm{MPa}^{1 / 2}\right)\end{array}$ \\
\hline Nonane & 15.8 & 0.0 & 0.0 \\
Ethyl acetate & 15.8 & 5.3 & 7.2 \\
Butyraldehyde & 14.7 & 5.3 & 7.0 \\
2-Butanone & 16.0 & 9.0 & 5.1 \\
Butyronitrile & 15.3 & 12.5 & 5.1 \\
\hline
\end{tabular}

The results show that increasing the polarity of the solvent leads to a decrease of the relative viscosity. In nonane, the relation between the polar parameter $\delta_{p}$ of the solvent and the relative viscosity is almost linear (Fig. 3). In naphtha, the efficiency is better than in nonane for the solvents that have a low polar parameter. Then, when the polar parameter becomes higher, the efficiency tends to a plateau (Fig. 4).

We can notice that for pure naphtha, the relative viscosity of the diluted oil is greater than for pure nonane (2800 versus 2300). Because of its aromatic content, naphtha is a good solvent of the asphaltenes. On the opposite, nonane is known to be a bad solvent for the asphaltenes. They can even precipitate if a large proportion of nonane is used. We can assume that the hydrodynamic volume of the asphaltenes particles is greater in naphtha than in nonane, making the entanglement of the colloidal particles of asphaltenes higher in naphtha than in nonane and therefore increasing the viscosity.

As the asphaltenes are more swollen in naphtha than in nonane, the polar sites of the asphaltenes are more reachable for the polar solvent. This can explain the greater efficiency of the polar solvents in naphtha than in nonane. One can think that the maximum in efficiency is reached when all the polar sites, even the weakest, are associated with solvent molecules. This is easier to obtain in naphtha, where the asphaltenes are relatively well solvated, than in nonane, where they are more compact. The best reduction of viscosity is reached in naphtha with butanone, and using an even more polar solvent like butyronitrile does not seem to improve the efficiency. This is not the case in nonane where, for all the studied solvents, the higher the value of the polar parameter, the better the efficiency.

\subsection{Influence of Hydrogen Bonding}

Following the same approach as for polarity, the influence of the hydrogen bonding parameter has been studied. The selected products and their Hansen parameters are listed in Table 4.

TABLE 4

Hansen parameters of hydrogen bonding solvents

\begin{tabular}{l|c|c|c}
\hline Solvent & $\begin{array}{c}\delta_{d} \\
\left(\mathrm{MPa}^{1 / 2}\right)\end{array}$ & $\begin{array}{c}\delta_{p} \\
\left(\mathrm{MPa}^{1 / 2}\right)\end{array}$ & $\begin{array}{c}\delta_{h} \\
\left(\mathrm{MPa}^{1 / 2}\right)\end{array}$ \\
\hline Octanoic acid & 15.1 & 3.3 & 8.2 \\
Butyric acid & 14.9 & 4.1 & 10.6 \\
1-octanol & 17.0 & 3.3 & 11.9 \\
1-butanol & 16.0 & 5.7 & 15.8 \\
Hexyl alcohol & 15.0 & 8.5 & 13.7 \\
\hline
\end{tabular}

Contrary to the polar solvents, it has not been possible to use mixtures of hydrogen bonding solvents with naphtha and nonane at the concentration of $50 \%$ volume. Indeed, due to their ability of giving hydrogen bonding, these solvents are viscous and the viscosity of the 50/50 v/v mixtures hide the

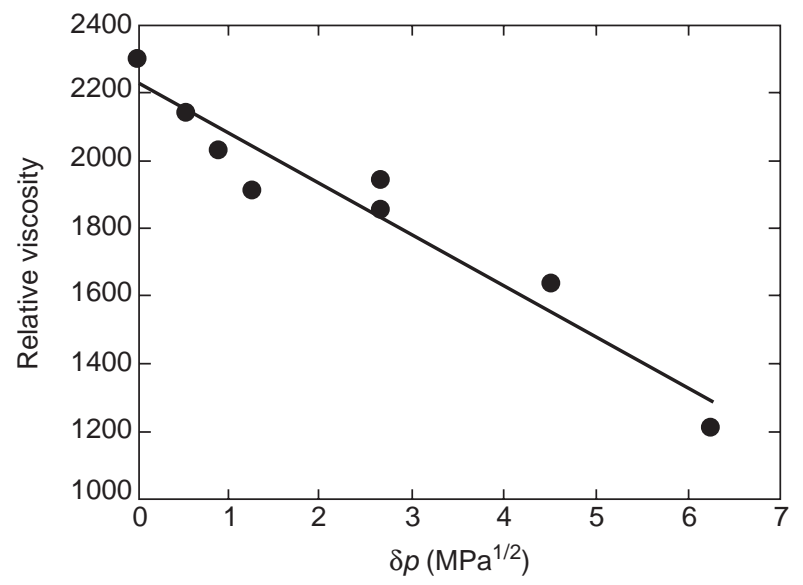

Figure 3

Evolution of the viscosity of dilute Oil A with the polarity of the nonane based solvent.

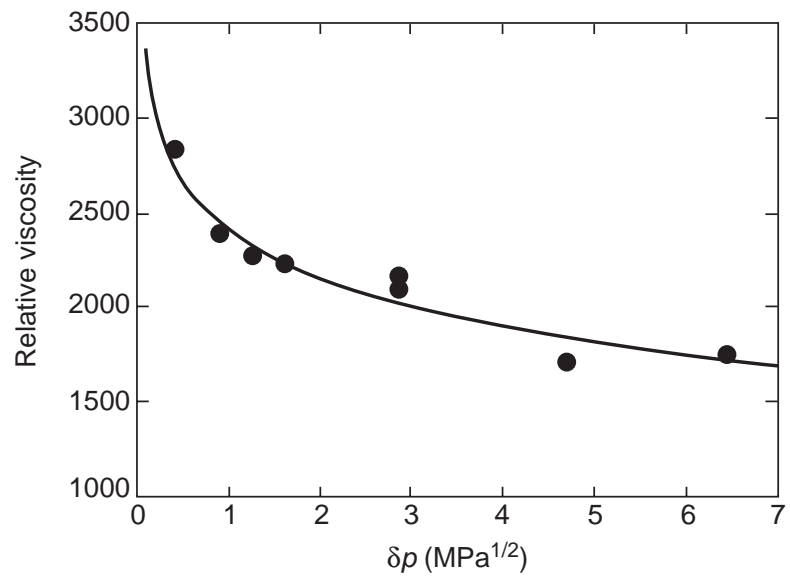

Figure 4

Evolution of the viscosity of dilute Oil A with the polarity of the naphtha based solvent. 


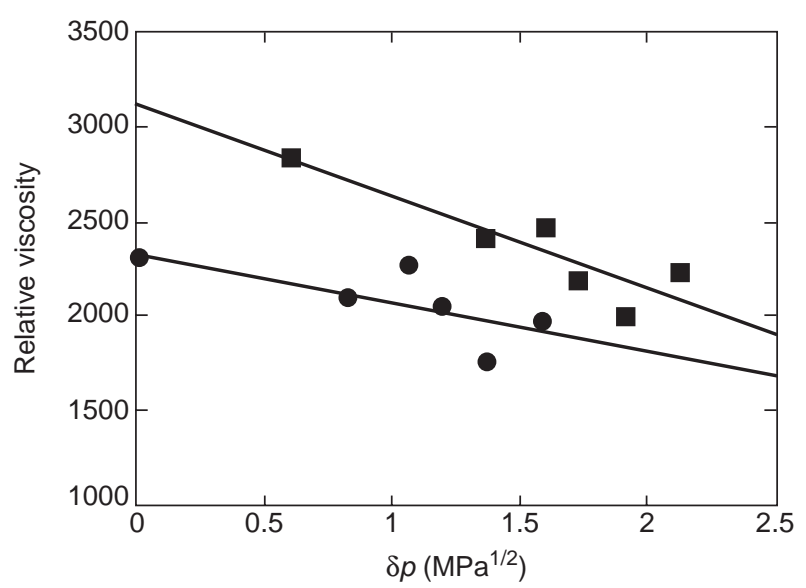

Figure 5

Evolution of the viscosity of dilute Oil A with the hydrogen bonding parameter of the solvent. Nonane based $(\bullet)$, naphtha based (ם).

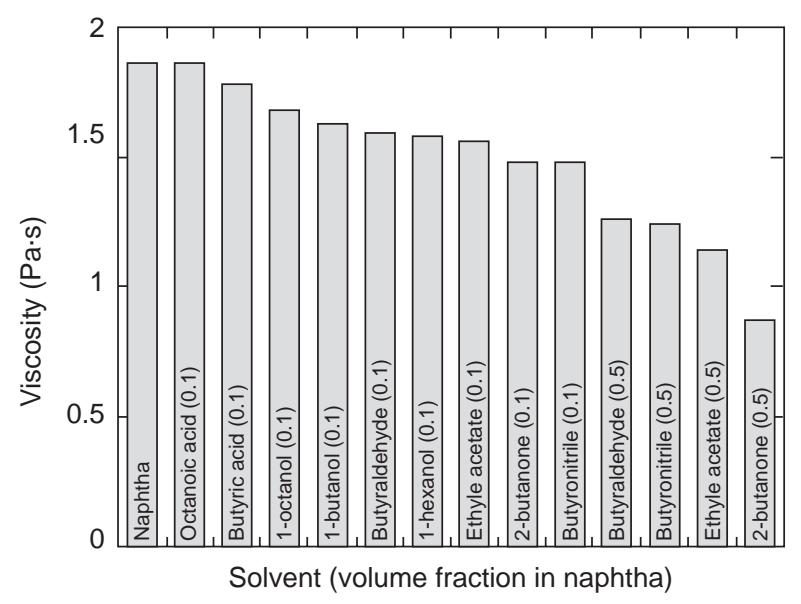

Figure 6

Absolute viscosity of Oil A at $20^{\circ} \mathrm{C}$ diluted with mixtures of naphtha and polar solvents. effect of these products on the asphaltenes. The resulting viscosity of the diluted crude was greater than that obtained with hydrocarbons alone. Therefore, the following tests have been conducted with Oil A diluted with $15 \%$ in weight of mixtures $90 / 10$ (by volume) of solvents and naphtha or nonane.

Increasing the hydrogen bonding parameters reduces the relative viscosity of the dilute crude in nonane as well as in naphtha (Fig. 5). However, there is no evident relationship between the $\delta_{h}$ parameter and the efficiency improvement. This probably comes from the dispersion of the values of the polarity parameter ranging from 3.3 to 8.5 . Moreover, probably coming from the high values of the two components $\delta_{p}$ and $\delta_{h}$, hexyl alcohol with a relative viscosity of 2004 with naphtha and of 1759 with nonane, is the most effective cosolvent. The solvents may be classified in the same order in naphtha and in nonane. Again, we found a better efficiency in naphtha than in nonane.

\subsection{Absolute Viscosity Reduction of Diluted Crude Oil}

We have seen that increasing the polarity or the hydrogen bonding capability of the solvent allows to reduce the relative viscosity of the diluted heavy oil. We have reported on Figure 6 the absolute viscosity of Oil A diluted with mixtures of naphtha and the different solvents previously used. Because of their high own viscosity, the products being characterized by high hydrogen bonding parameter do not improve dilution efficiency when used with naphtha.

Among the tested products, the most effective solvent is the 2-butanone. It leads to a significant reduction of the viscosity of the diluted oil when compared with pure naphtha.

\section{CONCLUSION}

By mixing hydrocarbons and solvents owning polar functional groups in their molecule, it is shown that the efficiency of the dilution of heavy crude oils is enhanced. Hansen's theory can be used as a guide to screen candidates solvents. At constant dilution rate, the higher the polarity of the solvent, the greater the viscosity reduction of the diluted crude oil, provided that the absolute viscosity of the solvent is close to the viscosity of the hydrocarbon. This excludes products owning high hydrogen bonding Hansen parameter.

Using such mixtures of solvents can help transporting heavy crude oils by increasing the quantity of transported oil, keeping constant the flow rate of the pipeline. In order to allow recycling, the boiling point of the cosolvent must fall in the boiling range of the hydrocarbon cut of the mixture. methyl ethyl ketone meets all these constraints and seems to be a good candidate for an industrial use.

\section{ACKNOWLEDGEMENTS}

This work has been performed through a collaborative study with TOTAL and was partly financially supported by the $F S H$ (Fonds de Soutien aux Hydrocarbures).

\section{REFERENCES}

1 Crandall, G.R. and Wise, T.H. (1984) Availability of Diluent May Inhibit Heavy Oil Exports. Can. Pet., 25, 37-40.

2 Urquhart, R.D. (1986) Heavy Oil Transportation: Present and Future. J. Can. Pet. Technol., 25, 2, 68-71.

3 Todd, C.M. (1988) Downstream Planning and Innovation for Heavy Oil Development - A Producer's Perspective. J. Can. Pet. Technol., 27, 1, 79-86. 
4 Guevara, E., Gonzalez, J., Nuñez, G. (1998) Highly Viscous Oil Transportation Methods in the Venezuela Industry. Proc. 15th World Pet. Congress, 495-502.

5 Meyer, R.F. (1998) World Heavy Crude Oil Resources. Proc. 15th World Pet. Congress, 459-471.

6 Mehrotra, A.K. (1992) A Model of the Viscosity of Bitumen/ Bitumen Fractions - Diluent Blends. J. Can. Pet. Technol., 31, 9, 28-32.

7 Gerez, J.M. and Pick, A.R. (1996) Heavy Oil Transportation by Pipeline. Int. Pipeline Conf., 2, 699-710.

8 Rahmes, M.H. and Nelson, W.L. (1948) Viscosity Blending Relationships of Heavy Petroleum Oils. Analytical Chemistry, 20, 912-915.

9 Shu, W.R. (1984) A Viscosity Correlation for Mixtures of Heavy Oil, Bitumen and Petroleum Fractions. SPE 11280.

10 Anhorn, J.L., Badakhshan, A. (1994) MTBE: A Carrier for Heavy Oil Transportation and Viscosity Mixing Rule Applicability. J. Can. Pet. Technol., 33, 4, 17-21.

11 Anhorn, J.L. and Badakhshan, A. (1994) Heavy Oil Oxygenates Blends and Viscosity Models. Fuel: Guildford, 73, 9, 1499-1503.
12 Storm, D.A. et al. (1999) Drag Reduction in Heavy Oil. Journal of Energy Resources Technology, 121, 145-148.

13 Argillier, J.F., Barré, L., Brucy, F., Dournaux, J.L., Hénaut, I. and Bouchard, R. (2001) Influence of Asphaltenes Content and Dilution on Heavy Oil Rheology. SPE 69711.

14 Lederer, E.L. (1933) Proc. World Pet. Cong. (Lond.) 2, 526528.

15 Zimm, B.H. (1948) The Scattering of Light and the Radial Distribution Function of High Polymer Solutions. J. Chem. Phys., 16, 1093-1116.

16 Fenistein, D. et al. (1998) Viscosimetric and Neutron Scattering Study of Asphaltene Aggregates in Mixed Toluene/Heptane Solvents. Langmuir, 14, 1013-1020.

17 Hénaut, I., Barré, L., Argillier, J.F., Brucy, F. and Bouchard, R. (2001) Rheological and Structural Properties of Heavy Crude Oils in Relation with Their Asphaltenes Content. SPE 65020.

18 Barton, A.F.M. (1992) Handbook of Solubility Parameters and Other Cohesion Parameters, 2nd Ed. CRC Press.

Final manuscript received in September 2004 